\title{
Use of Panoramic Radiographs to Detect Signs of Osteoporosis in Edentulous
}

\author{
Lílian Tedeschi Ramalli' ${ }^{1}$, Angela Jordão Camargo ${ }^{2 *}$, Solange Aparecida Caldeira Monteiro' ${ }^{1}$, \\ Plauto Christopher Aranha Watanabe ${ }^{1}$ \\ ${ }^{1}$ Department of Stomatology, Public Oral Health and Forensic Dentistry, Ribeirão Preto Dental \\ School, University of São Paulo, Ribeirão Preto, SP, Brazil \\ ${ }^{2}$ Department of Stomatology, School of Dentistry, University of São Paulo, São Paulo, SP, Brazil \\ Email: liliantr@usp.br, *dra.angelacamargo@gmail.com,solangeacm@forp.usp.br, \\ watanabe@forp.usp.br
}

Received 28 October 2015; accepted 13 December 2015; published 16 December 2015

Copyright (C) 2015 by authors and Scientific Research Publishing Inc.

This work is licensed under the Creative Commons Attribution International License (CC BY). http://creativecommons.org/licenses/by/4.0/

\section{Open Access}

\section{Abstract}

Objective: The objective is to analyze the importance of panoramic and carpal radiographs for evaluation of edentulous individuals in different ages, demonstrating the contribution of different dental radiographic techniques in detecting patients with signs of osteoporosis. Methods: The study was developed using panoramic and carpal digital radiographs of 30 edentulous women (age ranged 50 - 90 years). The panoramic radiographs was performed to measure the thickness of the mental index-MI and gonial index-GI, and evaluation of the morphology of the mandibular cortical shape (Klemetti classification). The carpal radiographs was performed to measure the cortical thickness of the $2 \mathrm{nd}$, 3rd and 4th metacarpals (metacarpal index). Statistics analyzed the relationship of these indices with the patient's age and the contribution of dental radiographs in detecting patients at risk for osteoporosis. Results: The average age of subjects was 68.43 years. In the analysis of cortical thickness of the panoramic radiographs, the mean values of mental index (MI) and gonial index (GI) for the age group 50 to 59 years were considered normal values ( $\geq 3.1 \mathrm{~mm}$ and $\geq 1.2 \mathrm{~mm}$, respectively). To analyze the morphology of the cortex, the $\mathrm{C} 3$ group corresponded to the majority of cases $(43.33 \%)$. The higher the age range, more morphological changes were observed (sum of the characteristics of groups $\mathrm{C2}$ and $(3)$. For the hand-wrist radiographs, the highest values of the metacarpal index (BMI) were found in the youngest age group ( 50 - 59 years). Conclusions: There was positive correlation between age and indices of quantitative assessment (IM, IG, BMI) and qualitative (analysis Klemetti) on panoramic and carpal radiographs. Age is a risk factor for the onset of osteoporosis.

${ }^{*}$ Corresponding author. 
Keywords

Panoramic Radiography, Elderly, Osteoporosis, Mandible, Metacarpus

\section{Introduction}

Increase in the elderly population in Brazil occurs quickly, being a reflection of the drop in fertility rate and increasing longevity, especially among women [1]. Population aging caused an epidemiological transition, changing the health profile of the population with a predominance of chronic diseases [2].

Data from IBGE (Brazilian Institute of Geography and Statistics) estimated that the proportion of elderly people over 65 years in 2010 would correspond to $6.83 \%$ of the population; and by 2050 this value will exceed $22.71 \%$ [3] [4].

The quality of life for seniors relates directly to the general health and the oral health condition. Tooth loss constitutes a major problem [5], causing individual changes in phonetic pattern, masticatory and aesthetic, implying changes in social behavior, emotional and psychological [6]. In order for the oral health of patients to be preserved, an important factor to be considered in the diagnosis and planning for any dental treatment is the presence of bone metabolic diseases, such as osteoporosis.

Osteoporosis is considered a public health problem by the World Health Organization (WHO), which mainly affects postmenopausal women [4]. The method considered the gold standard for diagnosis of bone metabolic disease is bone densitometry (DXA). However, due to cost and lack of public access to the examination in Brazil, use as screening method for osteoporosis is complicated [4] [7].

Alternative methods using dental radiographs (panoramic and carpal) to diagnose systemic osteoporosis were developed [4] [7]. Panoramic radiography, which was already part of routine prosthetic planning, to diagnose alterations in jaws, presence of root fragments, foreign bodies, bone ridge height, could also be used to assess systemic conditions [8] and found a significant correlation between changes in trabecular bone seen on panoramic radiographs and wrist radiographs (carpal) with osteoporosis in the spine and femur, detected by bone densitometry [7].

\section{Methods}

The study was conducted using digital radiographic of 30 edentulous women, aged between 50 - 90 years. The inclusion criteria were edentulous women who received care at the Prosthodontics Course in Ribeirão Preto Dental School (University of São Paulo) and were forwarded to radiology service. This prosthodontics care occurred after radiological documentation. All subjects agreed and signed the consensual term according of School of Dentistry policies.

The documentation was composed of panoramic and carpal radiographs, obtained from a digital equipment X-ray, Veraviewepocs (J. Morita. Corp., Kyoto, Japan). All images were analyzed with resolution of 300 dpi by Radio Imp Software 2.0 (Radio Memory, Belo Horizonte, Brazil).

In panoramic radiographs were performed measurements of mandibular cortex thickness, bilaterally in two places: the mentual foramen and mandibular angle. These measurements resulted in the Mentual Index (MI) and Gonial Index (GI).

For the measurement of Mentual Index (MI) was performed, at first, the design of the mental foramen. Next, a tangent was drawn to the mandibular border and perpendicular to this tangent line intersecting the top edge of the foramen. In parallel to this line was measured cortical thickness (Figure 1).

For the measurement of Gonial Index (GI), two lines were drawn: one tangential to the posterior edge of the branch and another tangential mandibular body. At the intersection of these two tangents, the angle was divided with a bisecting and parallel to that bisect, measurements were made of cortical of the mandibular angle (Figure 2).

Each index was made three readings for each side (right and left) and each patient by the same examiner, and the average of the measurements was used in the statistical analysis.

Panoramic radiographs were analyzed for the presence of osteoporotic sites, according to Klemetti [9] rating, 
Arquivo Listas Ferramentas Imagem Ajuda

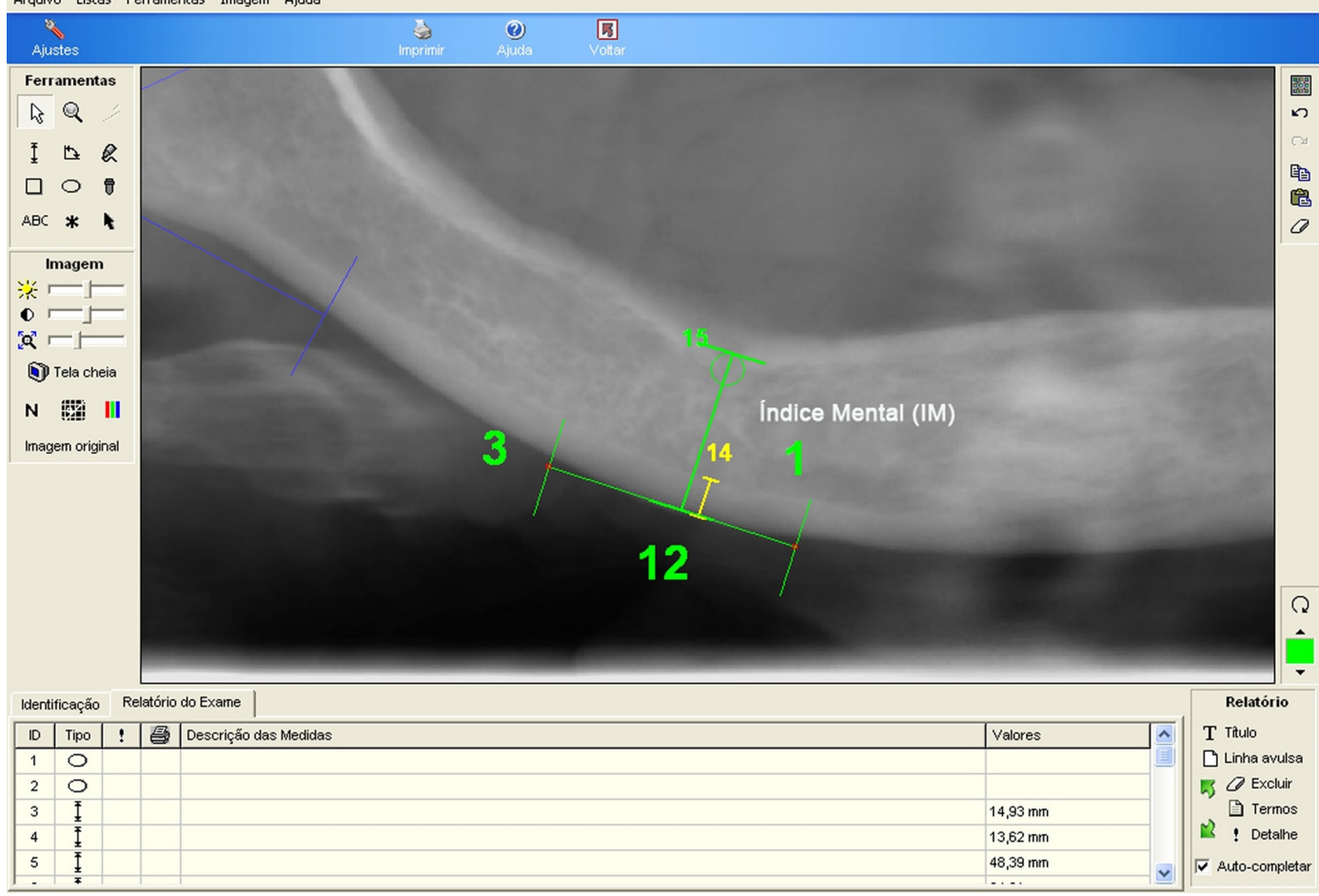

Figure 1. Measurement of the Mentual Index using the software program Radioimp (Radio Memory, Belo Horizonte, Brazil).

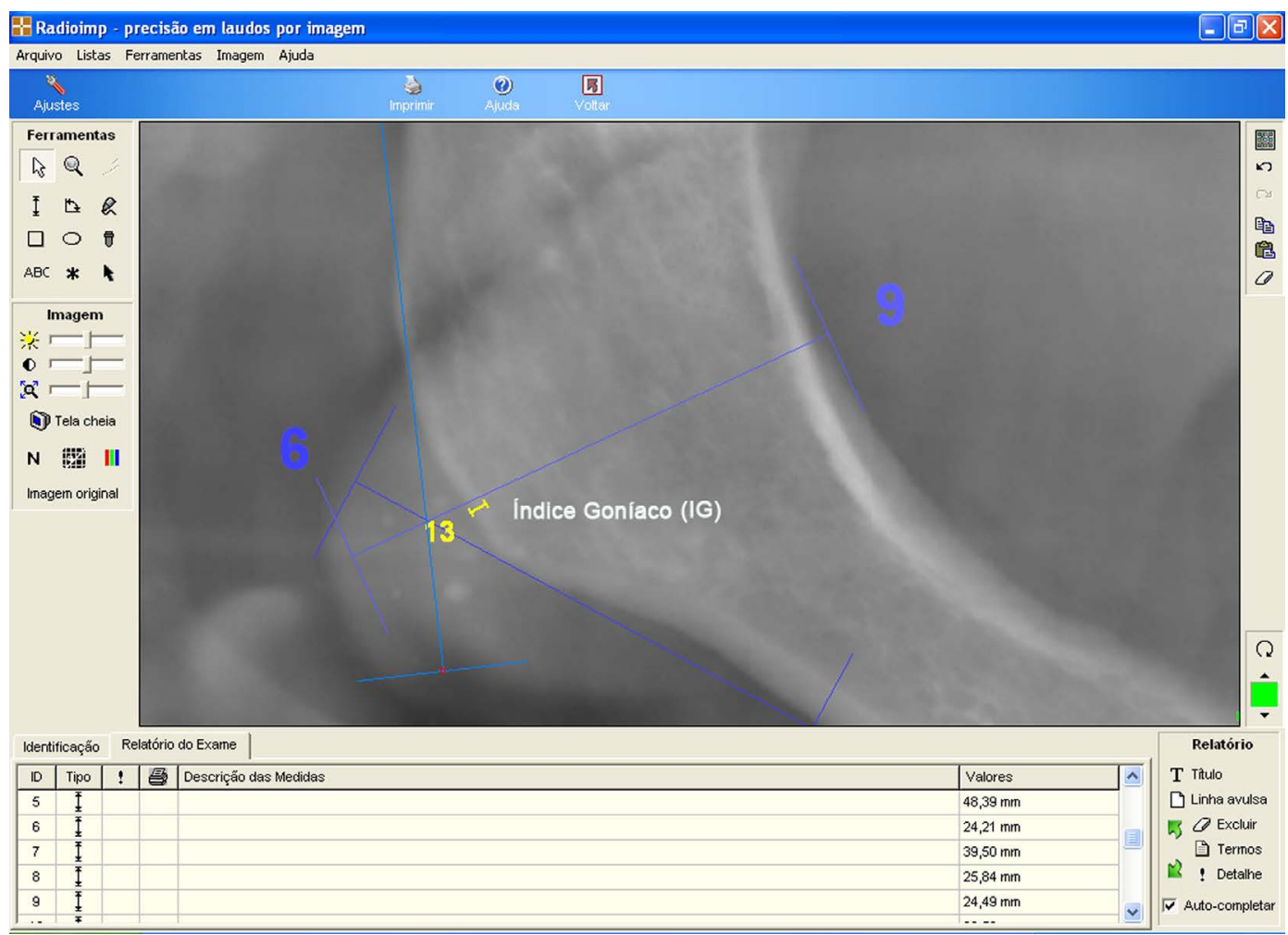

Figure 2. Measurement of the Gonial Index using the software program Radioimp (Radio Memory, Belo Horizonte, Brazil). 
which evaluates the lower cortex morphology. According to Klemetti (Figure 3), the radiographs are classified into three groups: C1 - the endosteal margin of the cortex was even and sharp on both sides; C2—the endosteal margin showed semilunar defects (lacunar resorption) or seemed to form endosteal cortical residues (one to three layers) on one or both sides; C3 - the cortical layer formed heavy endosteal cortical residues and was clearly porous. The classification was performed by a blind test and a single and experienced examiner, examined the entire sample, with help of image manipulation tools: brightness, contrast and zoom.

In carpal radiographs were performed measurements of the internal and external cortical thickness in 2nd, 3rd and 4th metacarpals. These measurements resulted in the Metacarpal Index (MCI) or Nordin Index (Figure 4).

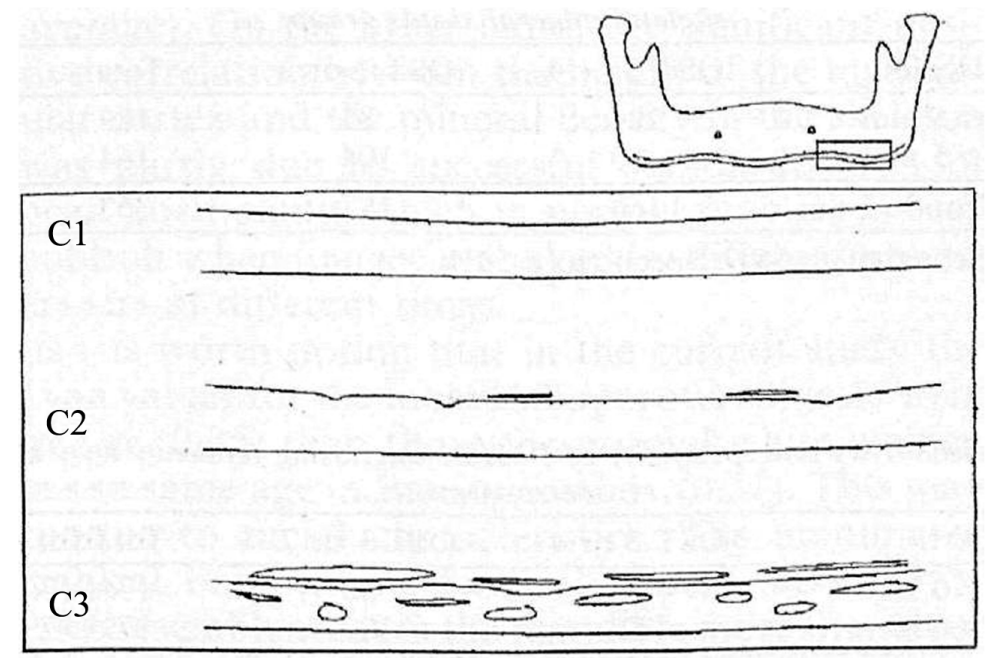

Figure 3. Classification according Klemetti (1994). Image was published in this article by Klemetti.

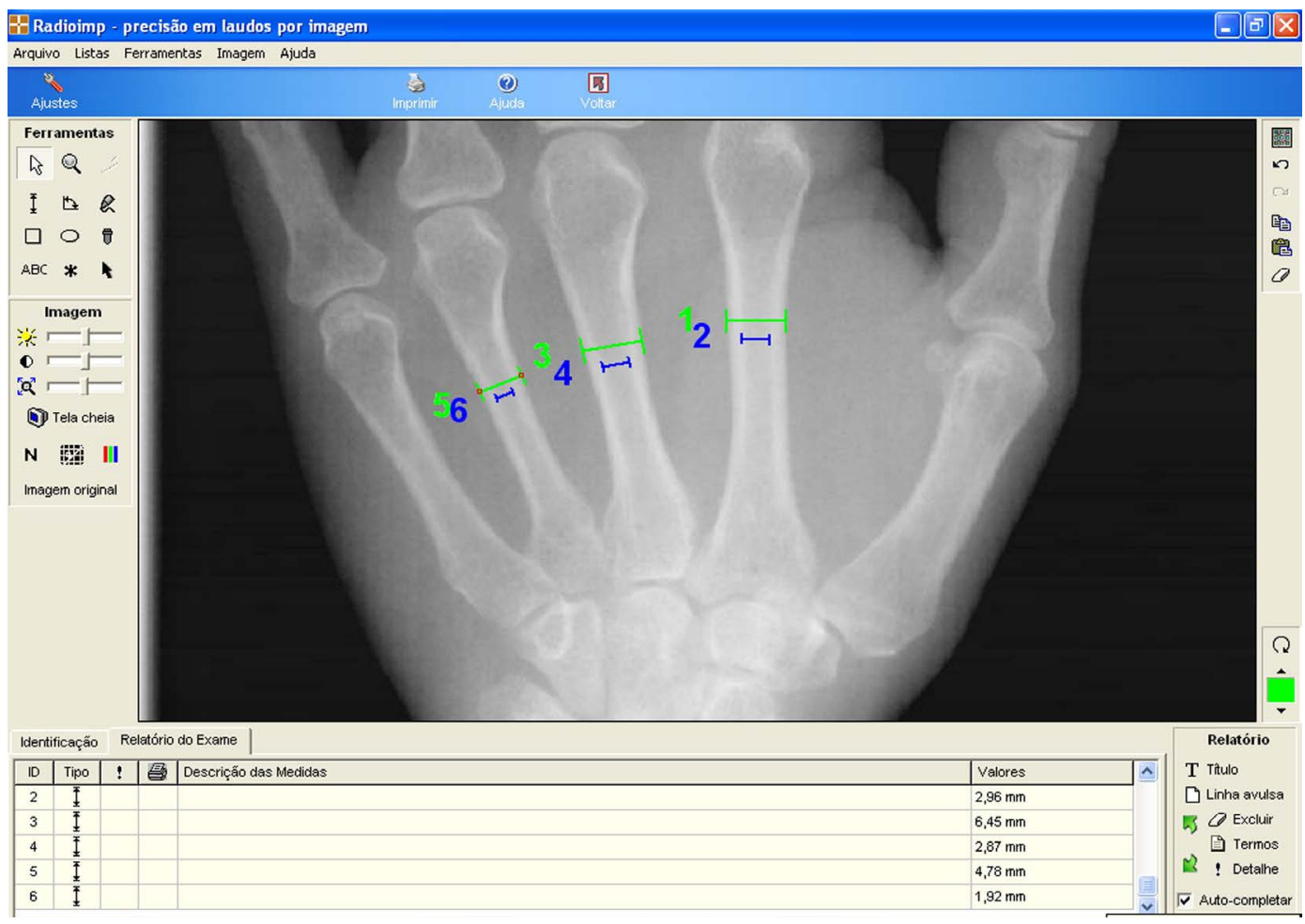

Figure 4. Measurement of Metacarpal Index (MCI) using the software program Radioimp (Radio Memory, Belo Horizonte, Brazil). 
Statistically was analyzed the relationship of MI, GI, Klemetti rating and MCI with the age of patients and the contribution of dental radiographs to detect patients with risk for osteoporosis. To analyze the panoramic $\mathrm{x}$-ray, comparisons were made through orthogonal contrasts using linear mixed-effects model. To verify the data correlation between right and left side of the radiograph, was used the Kappa coefficient, which ranges from 0 to 1 , when close to 0 is considered no correlation and close to 1 perfect correlation. Also was used descriptive analysis of researched indexes. For carpal radiographs was held a descriptive analysis of the variable.

This study was submitted to the Ethics Committee of the Ribeirão Preto Dental School and approved with protocol number 2009.1.382.58.2.

\section{Results}

Average age of subjects was 68.43 years. In panoramic radiograph, the cortical thickness analysis showed that the mean values of Mentual Index (MI) and Gonial Index (GI) for the age group 50 - 59 years had values considered within normal limits $(\geq 3.1 \mathrm{~mm}$ and $\geq 1.2 \mathrm{~mm}$, respectively) (Table 1). In the carpal radiographs, the highest values of metacarpal index (MCI) were found in the youngest age group (50 - 59 years) (Table 1).

The morphological cortex analysis, the C3 group corresponded to the majority of cases (43.33\%). The older the age, more morphologic changes were observed (sum of the characteristics of the C2 and C3) (Table 2).

\section{Discussion}

Osteoporosis is an osteometabolic disease characterized by low bone mass and micro architectural deterioration of tissue, leading to increased bone fragility and an increased fracture risk associated with high morbidity and mortality. One of the most common metabolic bone disorders in the elderly affects $30 \%$ of postmenopausal women [10] [11].

The first association of osteoporosis and bone loss in the maxilla and mandible in humans was performed by Groen, Duyvensz and Halsted, 1960 [4]. Osteoporosis results in decreased bone mass and changes the structure of maxillary, especially at the lower edge (tapering the inferior cortex of mandible] [10].

In this study, the average values of Mentual Index (MI) of the mandible cortical regarding age group 50 - 59 years had higher values than $3.1 \mathrm{~mm}$. In other age groups, the mean values were lower than $3 \mathrm{~mm}$ and decrease was progressive with increasing age. According to Horner and Devlin (2002) [6], measures of the inferior cortex of mandible below $3 \mathrm{~mm}$ was considered as a parameter for diagnosis of low bone mineral density.

In Gonial Index (GI), only in the age group 50 - 59 years the average values were greater than $1.2 \mathrm{~mm}$. Following the same pattern as MI, noted a progressive decrease in the GI in other age groups. In the age groups

Table 1. Radiomorphometric indices panoramic and carpal.

\begin{tabular}{cccccc}
\hline Age & Cases & Mean Age & $\begin{array}{c}\text { Mean and standard deviation } \\
\text { for MI }\end{array}$ & $\begin{array}{c}\text { Mean and standard deviation } \\
\text { for GI }\end{array}$ & $\begin{array}{c}\text { Mean and standard deviation } \\
\text { for MCI }\end{array}$ \\
\hline $50-59$ & $7(23.33 \%)$ & 55.14 & $3.15 \pm 1.22$ & $1.27 \pm 0.39$ & $0.53 \pm 0.07$ \\
$60-69$ & $7(23.33 \%)$ & 63.43 & $2.71 \pm 0.76$ & $0.97 \pm 0.27$ & $0.47 \pm 0.06$ \\
$70-79$ & $13(43.33 \%)$ & 74.15 & $2.48 \pm 0.06$ & $1.11 \pm 0.34$ & $0.47 \pm 0.02$ \\
$80-89$ & $3(10.00 \%)$ & 86.33 & $2.34 \pm 0.06$ & $0.84 \pm 0.08$ & $0.42 \pm 0.02$ \\
\hline
\end{tabular}

Table 2. Assessment of mandibular cortex morphology (Klemetti classification).

\begin{tabular}{|c|c|c|c|c|}
\hline \multirow[t]{2}{*}{ Age } & \multirow[t]{2}{*}{ Cases } & \multicolumn{3}{|c|}{ Klemetti Classification } \\
\hline & & C1 & $\mathrm{C} 2$ & C3 \\
\hline $50-59$ & $7(23.33 \%)$ & $42.86 \%$ & $14.28 \%$ & $42.86 \%$ \\
\hline $60-69$ & $7(23.33 \%)$ & $28.57 \%$ & $42.86 \%$ & $28.57 \%$ \\
\hline $70-79$ & $13(43.33 \%)$ & $23.08 \%$ & $38.46 \%$ & $38.46 \%$ \\
\hline $80-89$ & $3(10.00 \%)$ & 0 & 0 & $100 \%$ \\
\hline
\end{tabular}


above 59 years, there was minor or borderline measures to that found by Bras et al. (1982) [5], which held that a cortical thickness of less than $1 \mathrm{~mm}$ in gonial angle is an indicator of metabolic bone loss.

Quantitative radiomorphometric indices, MI and the GI showed worsening with advancing age, pointing to decreased bone mass. These findings agree with data from studies of several authors [6] [12]-[14].

The morphological analysis of the mandibular cortical according to Klemetti, the C3 group (cortical clearly porous) corresponded to the majority of cases (43.33\%). The higher the age group, most morphological changes were observed. Qualitative analysis showed that in the younger age group (50 - 59 years) more than half of the sample had visible cortical bone loss, demonstrated by the sum of C2 and C3 groups (57.14\%).

In the carpal radiographs, the highest values of metacarpal index (MCI) were found in the youngest age group (50 - 59 years), value declines with increasing age. The decline of the MCI in women is most pronounced during in the first 3 years after menopause [15] [16]. This association with age was also found by Coimbra et al. (1994) and Haara et al. (2006).

Several authors believe in the potential of using the metacarpal index (MCI) in epidemiological studies and in clinical practice [18] for being an affordable method, easy to obtain and low radiation involved. In this study, the analysis results of this index showed similar information to radiomorphometric indices measured on panoramic radiographs.

Age is a risk factor for osteoporosis, as could be seen with the drop in index values in the older age groups [18]-[20].

The increase of the elderly population therefore osteoporosis, the dentist has the opportunity to treat often the older age groups, since the large number of edentulous in Brazil. Becomes of great value that routine radiographs in dental treatments can provide subsidy for the analysis of early signs of the disease, allowing these health professionals appropriately refer their patients to the proper medical care.

\section{Conclusion}

In conclusion, panoramic radiograph allows oral overview of the patient's condition (detection of residual roots, impacted teeth, disease and anatomical accidents) and constitutes an important research site for signs of osteoporosis. The realization of carpal radiography has not shown to be essential if there is a panoramic radiograph for bringing similar information (radiomorphometric indices) in relation to osteoporosis. However, carpal radiography is more accessible since it can be performed in various radiographic apparatus. There was positive correlation between age and indices of quantitative assessment (IM, IG, BMI) and qualitative (analysis Klemetti) on panoramic and carpal radiographs. Age is a risk factor for the onset of osteoporosis.

\section{References}

[1] Bassi, F., Rizzatti, A., Schierano, G. and Preti, G. (2001) Evaluation of the Utility of Cephalometric Parameters in Constructing Complete Denture. Part II: Placement of Anterior Teeth. Journal of Oral Rehabilitation, 28, 349-353. http://dx.doi.org/10.1046/j.1365-2842.2001.00668.x

[2] Amorin, V.C.P., Laganá, D.C., Eduardo, J.V.P. and Zanetti, A.L. (2003) Analysis of the Condyle/Fossa Relationships before and after Prosthetic Rehabilitation with Maxillary Complete Denture and Mandibular Removable Partial Denture. Journal of Prosthetic Dentistry, 89, 508-514. http://dx.doi.org/10.1016/S0022-3913(03)00029-5

[3] Campostrini, E.P., Ferreira, E.F. and Rocha, F.L. (2007) Conditions of the Oral Health of the Brazilian Elderly. Arquivos em Odontologia, 43, 48-56.

http://bases.bireme.br/cgi-bin/wxislind.exe/iah/online/?IsisScript=iah/iah.xis\&src=google\&base=LILACS\&lang=p\&ne xtAction=lnk\&exprSearch=518057\&indexSearch=ID

[4] Costa, C.B. (2009) Evaluation of the Golden Ratio in Lateral Cephalometric Radiographs of Edentulous Individuals before and after Treatment by Complete Dentures. Master Dissertation, São José dos Campos Dental School, São José dos Campos. http://hdl.handle.net/11449/98011

[5] Bras, J., van Ooij, C.P., Abraham-Inpijn, L., Kusen, G.J. and Wilmink, J.M. (1982) Radiographic Interpretation of the Mandibular Angular Cortex: A Diagnostic Tool in Metabolic Bone Loss. Part I. Normal state. Oral Surgery, Oral Medicine, Oral Pathology and Oral Radiology, 53, 541-545. http://dx.doi.org/10.1016/0030-4220(82)90473-X

[6] Devlin, H. and Horner, K. (2002) Mandibular Radiomorphometric Indices in the Diagnosis of Reduced Skeletal Bone Mineral Density. Osteoporosis International, 13, 373-378. http://dx.doi.org/10.1007/s001980200042

[7] Çiftçi, Y., Kocadereli, I., Canay, Ş. and Şenyılmaz, P. (2005) Cephalometric Evaluation of Maxillomandibular Rela- 
tionships in Patients Wearing Complete Dentures. The Angle Orthodontist, 75, 821-825.

[8] Dias, A.T., Soares, R.O., Lima, W.M. and Sá, M.V. (2006) Vertical Dimension of Occlusion in Complete Denture. Odontologia Clin Cientif, 5, 41-47.

[9] Klemetti, E., Kolmakov, S. and Kroger, H. (1994) Pantomography in Assessment of the Osteoporosis Risk Group. Scandinavian Journal of Dental Research, 102, 68-72. http://dx.doi.org/10.1111/j.1600-0722.1994.tb01156.x

[10] Brzoza, D., Barrera, N., Contasti, G. and Hernández, A. (2005) Predicting Vertical Dimension with Cephalograms, for Edentulous Patients. Gerodontology, 22, 98-103. http://dx.doi.org/10.1111/j.1741-2358.2005.00060.x

[11] Evans, R.A., McDonnell, G.D. and Schieb, M. (1978) Metacarpal Cortical Area as an Index of Bone Mass. The British Journal of Radiology, 51, 428-431. http://dx.doi.org/10.1259/0007-1285-51-606-428

[12] Balcikonyte, E., Balciuniene, I. and Alekna, V. (2004) Panoramic Radiographs in Assessment of the Bone Mineral Density. Stomatologija, 6, 17-9.

[13] Mahl, C.R.W., Licks, R. and Fontanella, V.R.C. (2008) Comparison of Orphometric Indices Obtained from Dental Panoramic Radiography for Identifying Individuals with Osteoporosis/Osteopenia. Radiologia Brasileira, 41, 183-187. http://dx.doi.org/10.1590/S0100-39842008000300011

[14] Alonso, M.B.C.C., Cortes, A.R.G., Camargo, A.J., Arita, E.S., Haiter-Neto, F. and Watanabe, P.C.A. (2011) Assessment of Panoramic Radiomorphometric Indices of the Mandible in a Brazilian Population. ISRN Rheumatology, 2011, Article ID: 854287. http://dx.doi.org/10.5402/2011/854287

[15] Nielsen, S.P. (2001) The Metacarpal Index Revisited: A Brief Overview. Journal of Clinical Densitometry, 4, $199-207$. http://dx.doi.org/10.1385/JCD:4:3:199

[16] Vehmas, T., Solovieva, S., Riihimäki, H., Luoma, K. and Leino-Arjas, P. (2005) Hand Workload and the Metacarpal Cortical Index. A Study of Middle-Aged Teachers and Dentists. Osteoporosis International, 16, 672-680. http://dx.doi.org/10.1007/s00198-004-1742-y

[17] Coimbra, A.M.V., Janovistz, D.Y. and Marques Neto, J.F. (1994) The Value of Radiological Assessment in Post-Menopausal Osteoporosis. Revista Brasileira de Reumatologia, 34, 161-166. http://bases.bireme.br/cgi-bin/wxislind.exe/iah/online/?IsisScript=iah/iah.xis\&src=google\&base=LILACS\&lang=p\&ne xtAction=lnk\&exprSearch=169245\&indexSearch=ID

[18] Haara, M., Heliövaara, M., Impivaara, O., Arokoski, J. P., Manninen, P., Knekt, P. and Kröger, H. (2006) Low Metacarpal Index Predicts Hip Fracture: A Prospective Population Study of 3561 Subjects with 15 Years of Follow-Up. Acta Orthopaedica, 77, 9-14. http://dx.doi.org/10.1080/17453670610045632

[19] Ariton, S.G., Pauna, M. and Mihai, G.I. (2008) Cephalometric Evaluation of the Maxillomandibular Relationships of a Patient Wearing Complete Dentures. TMJ, 58, 87-90.

[20] Camargo, A.J., Arita, E.S., Fenandez, M.C.C. and Watanabe, P.C.A. (2015) Comparison of Two Radiological Methods for Evaluation of Bone Density in Postmenopausal Women. International Journal of Morphology, 33, 732-736. http://dx.doi.org/10.4067/S0717-95022015000200050 